\title{
Efficacy of Perioperative Intravenous Lidocaine for Multimodal Analgesia
}

\author{
Nishita Lockwood, Lopa Misra \\ Department of Anesthesiology, Mayo Clinic Arizona, Phoenix, AZ, USA \\ Email: nishitalockwood@email.arizona.edu
}

How to cite this paper: Lockwood, N. and Misra, L. (2020) Efficacy of Perioperative Intravenous Lidocaine for Multimodal Analgesia. Open Journal of Anesthesiology, 10, 299-312.

https://doi.org/10.4236/ojanes.2020.109027

Received: July 9, 2020

Accepted: September 24, 2020

Published: September 27, 2020

Copyright $\odot 2020$ by author(s) and Scientific Research Publishing Inc. This work is licensed under the Creative Commons Attribution International License (CC BY 4.0).

http://creativecommons.org/licenses/by/4.0/ (c) (i) Open Access

\begin{abstract}
Given the rising incidence of opioid misuse and opioid-related deaths worldwide, it is imperative to find nonopioid analgesic adjuncts for perioperative pain management. Perioperative opioid exposure in opioid-naïve patients for even minor surgical procedures may result in significant opioid dependence. Although the use of intravenous lidocaine in the perioperative period is not novel, recently it has been proposed as an important adjunct to multimodal analgesia. In addition to improving acute pain, lidocaine may reduce the incidence of chronic post-operative pain syndrome (CPPS), improve bowel function, and decrease post-operative nausea and vomiting (PONV) thereby speeding up the post-operative recovery process. Furthermore, lidocaine has efficacy in a variety of procedures including abdominal, gynecological, and urological surgeries. The aim of this narrative review is to evaluate the effects of intravenous lidocaine compared to traditional analgesic methods on post-operative pain control and recovery for various surgical procedures.
\end{abstract}

\section{Keywords}

Pain Management, Opioid Addiction, Intraoperative Pain Control, Non-Opioid Analgesia

\section{Introduction}

According to the World Health Organization, over 250 million surgical operations are performed annually worldwide. One of the most common complications of surgery is inadequate post-operative pain control. Acute to persistent post-operative pain is thought to occur in nearly half of individuals undergoing surgery [1]. Furthermore, the incidence of chronic post-surgical pain (CPSP) is rising dramatically, even in commonly performed surgical procedures such as mastectomies and laparoscopic cholecystectomies [2] [3]. CPSP is defined as 
pain of at least two months duration that develops after a surgical procedure in which no other cause is identified. It is thought to arise from poorly controlled acute pain, which occurs post-operatively. There are a variety of risk factors attributable to chronic post-surgical pain including patient background, surgical, and pre-, intra-, and post-operative considerations. Pre-operatively, age, female gender, catastrophizing, history of chronic pain, history of chronic pain medication use have all been associated with increased incidence of CPSP. The surgical approach and technique is also a recognized risk factor for chronic pain development. Specifically, certain surgical approaches are more likely to result in nerve injury, as well as open versus laparoscopic surgeries. Finally, poor post-operative pain control is strongly correlated with progression to CPSP [4]. CPSP is associated with a number of negative health outcomes including delayed recovery, prolonged hospital stay, and increased patient dissatisfaction [5]. One of the most important ways to prevent CPSP is aggressive treatment of acute perioperative and intraoperative pain. Therefore, it is imperative to have appropriate multimodal perioperative pain management in order to alleviate acute pain and reduce the incidence of CPSP.

The most commonly prescribed analgesics to relieve postoperative pain are opioids. However, since 2000 the rate of opioid use has dramatically increased, resulting in a four-fold increase in opioid-related overdoses [6]. Of the 63,632 drug overdose deaths in the US in 2016, nearly two thirds were thought to be due to opioids [7]. Opioids have become the second most common cause of poisoning, behind alcohol, seen in US emergency departments and have surpassed motor vehicle accidents in unintentional deaths [8] [9]. A patient's first exposure to opioids is likely in the perioperative setting, where anesthesiologists play a major role. An estimated $99 \%$ of patients receive opioids perioperatively [10]. Opioid use perioperatively may lead to increased opioid use postoperatively [11]. With the rising incidence of opioid misuse and opioid-related overdoses, it is important to consider non-opioid analgesics for management of pain perioperatively.

Recent studies have evaluated the use of multimodal nonopioid analgesia in the perioperative setting. Perioperative use of non-opioid medications such as cox 1 and 2 inhibitors, gabapentin, and acetaminophen have been shown to decrease the use of opioids postoperatively. In addition, recent literature has shown that lidocaine may be an important adjunct in managing perioperative pain. Lidocaine is a local amide anesthetic that has been efficacious in treating neuropathic cancer pain and chronic pain [12]. Lidocaine may play an important role in the intraoperative management of pain and reduce the incidence of post-operative pain. This review will expand on the literature related to intravenous lidocaine for postoperative pain control described by Kranke et al. in 2015 [13]. The purpose of this literature review is to investigate the efficacy of intraoperative lidocaine infusions for management of acute pain and chronic pain for various surgical procedures. 


\subsection{Pharmacodynamics}

Lidocaine has analgesic, anti-hyperalgesic, anti-inflammatory, and antiarrhythmic properties. Furthermore, it is believed to exert its analgesic effects by causing reversible inhibition of neuronal action potential propagation. It acts by binding to voltage-gated sodium channels, inducing a conformational change which prevents the influx of sodium ions and subsequent depolarization. This increases the threshold for excitability and reduces action potential propagation [14]. In addition, lidocaine acts on voltage-dependent potassium and calcium channels, however with reduced affinity compared to sodium channels. Blockage of potassium channels may result in decreased pain intensity and decreased tissue ischemia. Furthermore, blockage of calcium channels results in reduced neurotransmitter release [15]. Lidocaine is also thought to have anti-inflammatory effects by blocking the release of interleukin-1; however the entire mechanism of action is not yet fully understood. Lidocaine is a class Ib antiarrhythmic medication that exerts its effects by acting directly on His-Purkinje fibers. It inhibits influx of sodium ions, decreasing conduction velocity in phase 0 of the cardiac myocyte actional potential. Furthermore, it causes a decrease in phase 4 of the cardiac action potential, leading to decreased action potential length and increase in refractory period.

\subsection{Pharmacokinetics}

Lidocaine has a rapid onset of action and short duration. Absorption of lidocaine is dependent on dose, route of administration, and vascularity of the site. It exerts its effects approximately 1 to 5 minutes after subcutaneous administration and 45 - 90 seconds after intravenous injection. In nerve blockades, onset of action occurs 5 - 15 minutes after injection with peak levels occurring $20-30 \mathrm{mi}$ nutes after injection. When used intravenously, lidocaine is initially distributed to highly vascularized structures first including the liver, heart, lungs, and brain, with a large volume of distribution of $0.6-4.5 \mathrm{~L} / \mathrm{kg}$. Lidocaine is primarily metabolized by the cytochrome P450 system in the liver therefore patients with cirrhosis may require lower doses due to decreased plasma clearance. In patients with congestive heart failure, the volume of distribution and clearance are reduced, and therefore patients may require smaller doses. The elimination of lidocaine generally follows linear pharmacokinetics with a half-life of approximately 1.5 - 2 hours after bolus or infusion lasting less than 12 hours. After 12 hours, lidocaine exerts time-dependent rather than linear elimination and may have a half-life up to 4 hours [16].

\subsection{Adverse Effects}

Lidocaine toxicity can occur when it is administered at high doses or when injected intravascularly. Central nervous system toxicity results in circumoral numbness, tinnitus, vertigo, and restlessness. Cardiac effects include hypotension, cardiac arrest, PR interval prolongation, and QRS widening [17]. Con- 
traindications to lidocaine use include patients with known history of adverse reaction or allergy to lidocaine or other amides, heart block, severe cardiac failure, severe hepatic or renal impairment and seizure disorder [18].

\section{Material and Methods}

The authors performed a comprehensive search of the literature with MEDLINE and Pubmed by using the Medical Subject Headings (MeSH) terms lidocaine infusion, chronic postoperative pain syndrome, local anesthetics, perioperative analgesia. Each term was searched with an "or" with the other terms and individually. All articles within the past 20 years were included. Systematic reviews and randomized controlled trials that evaluate the effect of intravenous lidocaine infusion on postoperative pain and/or recovery in patients undergoing a surgical procedure were included. Articles that did not compare lidocaine to a control or another analgesic method were not included. A total of 27 articles were included.

\section{Surgical Indications}

\subsection{Abdominal Surgery}

\subsubsection{Laparoscopic}

Intravenous lidocaine has been shown to be efficacious in a number of abdominal surgeries. Studies have demonstrated that a perioperative lidocaine infusion is superior to placebo in reducing post-operative pain. In an RTC of 50 participants undergoing laparoscopic colectomy, patients were assigned to receive either a lidocaine or saline infusion. Lidocaine was administered as a bolus at induction of $1.5 \mathrm{mg} / \mathrm{kg}$ followed by a $2 \mathrm{mg} / \mathrm{kg} / \mathrm{hr}$ infusion and no other analgesics were provided intraoperatively. At the 24 -hour post-operative period, patients who received lidocaine reported significantly lower pain scores than those in the saline group ( 24 vs. 29 VAS, $\mathrm{p}<0.05$ ). In addition, the total fentanyl consumption required was lower in the lidocaine group $(890 \mu \mathrm{g}$ vs. $1020 \mu \mathrm{g}, \mathrm{p}=$ 0.039 ) and the frequency of button pushing for the PCA pump was lower (35 vs $45, \mathrm{p}<0.001)$ postoperatively. The lidocaine group also had significantly lower PONV scores $(\mathrm{p}=0.023)$ than the saline group. This is likely due to the reduced fentanyl requirement in the lidocaine group. There was no difference found in length of stay between the two groups; however the lidocaine group reported greater satisfaction likely due to greater pain control and decreased PONV [19]. PONV and pain contribute significantly to patient satisfaction and may prolong hospital stays. This study demonstrated that lidocaine infusions may enhance patient recovery. Studies have also suggested lidocaine may be a better option than dexmedetomidine for pain control. In a randomized controlled trial of 59 patients undergoing hemicolectomies, lidocaine infusion at $1.5 \mathrm{mg} / \mathrm{kg} / \mathrm{hr}$ was compared to dexmedetomidine infusion at $0.5 \mu \mathrm{g} / \mathrm{kg} / \mathrm{h}$. Lidocaine was found to have more analgesic effects two days post-operatively than dexmedetomidine. The total amount of piritramide, a synthetic opioid analgesic given parenterally and primarily used in European countries, consumed was $1.133 \mathrm{mg} / \mathrm{kg}$ in the li- 
docaine group versus $1.172 \mathrm{mg} / \mathrm{kg}$ in the dexmedetomidine group. There was no significant difference in length of hospital stay between the two groups [20]. Bariatric patients may also benefit from lidocaine infusions peri- and intra-operatively. A lidocaine bolus of $1.5 \mathrm{mg} / \mathrm{kg}$ followed by a $2 \mathrm{mg} / \mathrm{kg} / \mathrm{h}$ infusion resulted in reduced post-operative pain score and improved quality of recovery in a study of 51 patients who received lidocaine compared with saline $(p=0.01)$. Furthermore, less morphine was consumed in the lidocaine group compared to the saline group ( $26 \mathrm{mg}$ vs. $36 \mathrm{mg}, \mathrm{p}=0.03$ ). In this study lidocaine served as a component of multi-modal analgesia. In addition to lidocaine, patients received other intraoperative opioids and surgical site bupivacaine injections [21]. In a study of 83 patients undergoing appendectomies, patients were randomized to receive lidocaine or saline intraperitoneally or intravenously. $1.5 \mathrm{mg} / \mathrm{kg}$ bolus followed by a $2 \mathrm{mg} / \mathrm{kg} / \mathrm{h}$ infusion resulted in reduced VAS score, fentanyl consumption and decreased PONV [22].

\subsubsection{Open Surgery}

In a double-blind RTC, 36 patients undergoing subtotal gastrectomy received either lidocaine or saline infusions. Similar to the prior study, lidocaine was given as a $1.5 \mathrm{mg} / \mathrm{kg}$ bolus followed by an infusion of $2 \mathrm{mg} / \mathrm{kg} / \mathrm{hr}$ with no other intraoperative analgesics. VAS pain scores up to 24 hours post-operatively were lower in the lidocaine group. Total amount of fentanyl use (1931 $\mu \mathrm{g}$ vs. $2339 \mu \mathrm{g}$, $\mathrm{p}<0.007$ ) and frequency of PCA button pushed (49 vs. 76, $\mathrm{p}=0.003$ ) were significantly lower in the lidocaine group [23]. In major abdominal surgeries, perioperative lidocaine infusion has been shown to be as efficacious as an epidural analgesia. In a retrospective review of 216 patients who received $1 \mathrm{mg} / \mathrm{kg} / \mathrm{hr}$ of intravenous lidocaine, post-operative pain scores were similar to patients who received an epidural. In addition, lidocaine was superior to epidural in terms of return of bowel function, urinary catheter removal, and PONV [24]. However, a previous study of 60 patients randomized to receive a thoracic epidural versus intravenous lidocaine of the same amount $(2 \mathrm{mg} / \mathrm{kg}$ followed by $3 \mathrm{mg} / \mathrm{kg} / \mathrm{hr}$ ) found that the epidural group had improve pain score, lower opioid consumption, and return of bowel function compared to those that received intravenous lidocaine [25]. Lidocaine may also be as effective as epidural analgesia in patients undergoing colon surgery. In an RTC of 22 patients, there was no difference in terms of bowel function, duration of hospital stay, or pain control in patients who received either an epidural of $0.125 \%$ bupivacaine and hydromorphone 6 micrograms/mL or intravenous lidocaine at $1 \mathrm{mg} / \mathrm{min}$ [26]. In addition to reduction in PONV, lidocaine has been shown to improve bowel function post-operatively. In a meta-analysis of eight trials including both laparoscopic and open surgeries, lidocaine infusion decreased the duration of ileus by nearly eight hours [27]. There were no side effects to lidocaine infusions in these studies, suggesting it is a safe analgesic agent at these doses.

In summary, there is evidence to suggest intravenous lidocaine alone may provide sufficient analgesic in patients undergoing abdominal surgery in addi- 
tion to being an important component of multi-modal analgesia.

\subsection{Breast Surgery}

There are conflicting data on whether lidocaine benefits patients undergoing breast surgery. In an RCT of 71 patients undergoing mastectomies for breast cancer, patients were assigned to receive either lidocaine $1.5 \mathrm{mg} / \mathrm{kg}$ bolus at induction and infusion at $2 \mathrm{mg} / \mathrm{kg} / \mathrm{h}$ or placebo in addition to traditional intraoperative opioids. There was no significant difference in intraoperative or postoperative opioid consumption, pain score, or PONV between the two groups [28]. However, a subgroup analysis of these patients showed that lidocaine infusion was significantly associated with decreased incidence of chronic post-surgical pain syndrome six months post-operatively. This was determined by calling patients six months after their mastectomies and asking a series of questions to evaluate whether they had CPSP. Of the 12 patients who answered the call, 8 in the placebo group and 4 in the lidocaine group reported signs of CPSP. There are a number of proposed mechanisms for the development of CPSP. A few prominent theories include increased sensitization at peripheral or central nociceptors or inflammatory changes that lead to chronic pain [29]. This is an important concept as chronic pain after breast surgery affects 25 to $60 \%$ of patients. One of the biggest risk factors to the development of chronic pain is thought to be poorly controlled acute post-surgical pain. Lidocaine may provide an important role in decreasing the incidence of post-surgical pain syndrome in breast surgery patients [30] Other studies have demonstrated that lidocaine has no effect postoperative pain control in breast surgery patients but does reduce the amount of inhaled anesthetic needed. In a study of 60 female patients undergoing elective breast surgeries, half were randomly assigned to receive a $1.5 \mathrm{mg} / \mathrm{kg}$ bolus of lidocaine followed by $1.5 \mathrm{mg} / \mathrm{kg} / \mathrm{hr}$ infusion versus control. No supplemental analgesics were given during the procedure. There was no significant difference in pain score, analgesic consumption, or patient satisfaction post-operatively between the two groups. However, the amount of sevoflurane required was 5\% less in the lidocaine group [31]. Furthermore, although lidocaine may not have a variable effect on post-operative pain need, it may be beneficial for long-term pain control. A recent pilot trial of 148 female patients demonstrated that intraoperative lidocaine vs saline in breast cancer surgery patients resulted in decreased incidence of persistent neuropathic pain although there was no impact on acute postoperative pain [32].

Thus far, it appears there is limited evidence to support that lidocaine will reduce opioid consumption intraoperatively and immediately postoperatively after breast surgery. There may be a long-term benefit in pain control, however more studies are needed to confirm this.

\subsection{Gynecological Surgery}

Few studies have evaluated the utility of perioperative lidocaine infusions in gy- 
necological surgery. In a study of 93 women undergoing hysterectomies, a 1.5 $\mathrm{mg} / \mathrm{kg}$ bolus followed by a $3 \mathrm{mg} / \mathrm{kg}$ lidocaine infusion was compared to placebo in a multimodal analgesic regimen. There was no difference in pain, length of hospital stay, or recovery between the two groups. In this study, acetaminophen and celecoxib were given preoperatively to all patients suggesting a potential confounder. The post-operative lidocaine period was variable for all patients, with a range of three hours to 24 hours [33]. A more recent of study of $45 \mathrm{pa}$ tients undergoing laparoscopic hysterectomies, found that patients who received a $1.5 \mathrm{mg} / \mathrm{kg}$ lidocaine bolus and $2 \mathrm{mg} / \mathrm{kg} / \mathrm{hr}$ infusion required less remifentanil intraoperatively than matched controls. In a follow-up RCT of 64 patients undergoing open hysterectomy, no difference was found in the six-minute walk test, opioid consumption, or pain score two days post-operatively in patients who received lidocaine infusions versus placebo [34]. These results conflict with a follow-up study of 40 patients who were randomly assigned to receive lidocaine at $2 \mathrm{mg} / \mathrm{kg} / \mathrm{hr}$ or saline at the same rate. The total amount of remifentanil administered was significantly lower than the saline group (472 $\mu \mathrm{g}$ vs $167 \mu \mathrm{g}, \mathrm{p}<$ 0.001 ) and the time to flatus and defecation was shorter in the lidocaine group compared to control (1972 minutes vs. 1452 minutes, $\mathrm{p}<0.001$ ). Furthermore, at six hours post-operatively there were fewer symptoms of PONV in the lidocaine group compared to the control although no difference was found at 24 hours [35]. This study demonstrates that lidocaine may improve pain in gynecological surgeries. These results were confirmed in a study of 50 patients undergoing laparoscopic gynecological surgery. Patients received a lidocaine bolus of $1 \mathrm{mg} / \mathrm{kg}$ followed by a lidocaine infusion or saline infusion. In patients that received lidocaine, there was shorter time to first flatus $(\mathrm{p}=0.02)$ and improved pain score $(\mathrm{p}=0.02)$ [36]. Lidocaine performs similarly to dexmedetomidine in post-operative pain control patients undergoing abdominal hysterectomies. There was no significant difference in VAS score 1 to 48 hours post-operatively using lidocaine or dexmetatomidine. However, lidocaine was associated with significantly shorter time to flatus $(\mathrm{p}<0.001)$ [37].

These studies demonstrate that lidocaine may reduce intraoperative opioid consumption, but there is not enough evidence supporting improved post-operative pain control in a multi-modal analgesic setting or alone.

\subsection{Urological Surgery}

Lidocaine infusions may reduce opioid consumption in men undergoing radical prostatectomies. In a study of $76 \mathrm{men}$, half were randomized to receive peri-operative lidocaine $2 \%$ or saline $0.9 \%$. Those that received a lidocaine infusion had a shorter hospital stay compared to the saline group (1.3 days vs. 4.6 days, $\mathrm{p}$ $=0.017)$. Those that received lidocaine were also able to mobilize faster (4.6 hours vs 22 hours, $\mathrm{p}=0.001$ ). Lidocaine reduced morphine consumption in the first 24 hours by a mean of $13.9 \mathrm{mg}$ versus. $53.4 \mathrm{mg}(\mathrm{p}=0.021)$. Finally, patients reported less pain during the first 24 hours after receiving a lidocaine infusion 
(p-0.001) [38]. In a previous study, patients who received intravenous lidocaine at $1 \mathrm{mg} / \mathrm{kg} / \mathrm{hr}$ during surgery and $2 \mathrm{mg} / \mathrm{kg} / \mathrm{hr} 24$ hours post-operatively had improvement in walking capacity post-operatively compared to saline $(\mathrm{p}<0.01)$ [39]. Hemodynamically, in patients undergoing radical prostatectomies, lidocaine reduced anesthetic requirements of volatile gas $(\mathrm{p}<0.001)$ and lowered mean arterial pressure $(80 \mathrm{mmHg}$ vs. $85 \mathrm{mmHg}, \mathrm{p}<0.001)$. No adverse effects were reported [40].

\subsection{Renal Surgery}

In a randomized, double-blind trial, lidocaine was given as a $1.5 \mathrm{mg} / \mathrm{kg}$ bolus during induction followed by an intraoperative infusion of $2 \mathrm{mg} / \mathrm{kg} / \mathrm{hr}$ and subsequently $1.3 \mathrm{mg} / \mathrm{kg} / \mathrm{hr} 24 \mathrm{~h}$ postoperatively. Compared to the placebo group, lidocaine infusion did not result in any difference in the length of hospital stay, opioid consumption, or return of bowel function [41]. Both lidocaine and ketamine reduced pains scores after a nephrectomy compared with control. In addition, morphine consumption was less in the lidocaine and ketamine groups compared to control (27 mg vs. $32 \mathrm{mg}$ vs. $47 \mathrm{mg}$ ). Lidocaine had the greatest effect on chronic neuropathic pain with a reduced incidence compared to both ketamine and control $(\mathrm{p}=0.006)$ [42]. Further studies are needed to evaluate the role of lidocaine in renal surgery.

\subsection{Colorectal Surgery}

Intravenous lidocaine may be similar to epidural in patients undergoing laparoscopic thoracic epidural. In a randomized controlled trial of 60 patients undergoing elective laparoscopic colorectal surgery, half were randomized to receive either thoracic epidural analgesia or IV lidocaine infusion of $1 \mathrm{mg} / \mathrm{kg}$ per hour with patient-controlled analgesia morphine for the first 48 hours after surgery. IV lidocaine and epidural had similar post-operative pain score, return of bowel function, and time to first flatus, suggesting IV lidocaine is a noninferior alternative to thoracic epidural.

\subsection{Orthopedic Surgery}

In patients undergoing hip arthroplasty, lidocaine infusion did not result in any significant pain reduction or mobility [34]. However, there may be a benefit to lidocaine infusion in patients with prior opioid use disorder undergoing orthopedic surgery. In a RCT of 180 patients undergoing a variety of orthopedic surgeries, patients were assigned to three groups: lidocaine infusion, normal saline, or ketamine. Those in the lidocaine group had lower pain score than the ketamine group $(\mathrm{P}<0.001)$. Morphine consumption was also lower in the lidocaine group compared to ketamine or control (14.49 mg vs $16.59 \mathrm{mg}$ vs. $21.72 \mathrm{mg}$ ). This suggests lidocaine may be an important component of multimodal therapy in treating opioid use disorder [43]. It would be useful to see if inclusion of a lidocaine infusion is beneficial in lowering the rate of chronic post surgical pain 
after total knee arthroplasties. Approximately $13 \%$ of patients will experience chronic pain after total knee arthroplasty [44].

\subsection{Spine Surgery}

Two studies have evaluated the use of intravenous intraoperative lidocaine in spine surgeries. In a study of 116 adults having complex spinal surgery, patients were assigned to receive either lidocaine $2 \mathrm{mg} / \mathrm{kg} / \mathrm{hr}$ or placebo during surgery. Lidocaine was superior to placebo in pain score $(\mathrm{p}<0.001)$ and opioid use $(\mathrm{p}=$ 0.011). No difference was found in length of stay or PONV. Lidocaine reduced opioid consumption, but the result was not significantly significant [45]. In contrast, a recent study demonstrated that lidocaine with a $1.5 \mathrm{mg} / \mathrm{kg}$ bolus followed by a $1.5 \mathrm{mg} / \mathrm{kg} / \mathrm{hr}$ infusion did not reduce opioid consumption or improve pain after posterior spinal arthrodesis [46].

\section{Conclusion}

With the increasing incidence of opioid-related deaths, it is imperative to find alternative treatments for pain management. Intravenous lidocaine has a number of benefits that make it a reasonable alternative analgesic for pain control. Studies have demonstrated it is an effective way to reduce post-operative opioid consumption, increase patient satisfaction and improve bowel function post-operatively. Many studies have relied on a dosing of $1.5 \mathrm{mg} / \mathrm{kg}$ bolus followed by a 2 $\mathrm{mg} / \mathrm{kg} / \mathrm{hr}$ infusion rate. Particularly in patients undergoing laparoscopic abdominal and gynecological surgery, lidocaine can reduce post-operative pain and opioid consumption. Further research is required in orthopedic and renal surgery. Although more research is needed to understand the long-term impact of lidocaine on pain management, it is a promising adjunct to pain management intraoperatively.

\subsection{Clinical Implications}

\section{Dosing/Surgeries}

Based on the current studies, a bolus of $1 \mathrm{mg} / \mathrm{kg}$ of lidocaine followed by a lidocaine infusion at $1.5-3 \mathrm{mg} / \mathrm{kg} / \mathrm{hr}$ for the duration of surgery is an effective dose for providing analgesia. This has been shown particularly in a variety of abdominal surgeries including colorectal and bariatric surgeries, as well as urological surgeries. Lidocaine may also have an important long-term role in patients undergoing breast surgery. Further research is needed to understand the role of lidocaine in renal, gynecological, and orthopedic surgeries. Lidocaine is a critical component of multimodal analgesia. It may be particularly useful in settings where there is no regional or acute pain service as it's been shown to be comparable to epidurals. Furthermore, in resource-limited settings, or in those with cost restraints, lidocaine has a clear advantage. It is similar to efficacy to dexmedetomidine but for nearly half the cost. In patients where opioids may be contraindicated, such as elderly population, those with severe existing pulmonary 
disease or opioid intolerance, lidocaine may be an appropriate substitute. For now, lidocaine is safe and cost-effective to use perioperative lidocaine for analgesia in patients undergoing a variety of surgeries and may even lead to improved recovery, return of bowel function, and decreased PONV.

\subsection{Future Considerations}

It is important to consider whether lidocaine should be used in patients receiving a TAP block for abdominal surgeries or whether lidocaine should be used as an alternative to a TAP block. TAP blocks are often performed with liposomal bupivacaine and the interaction of this and lidocaine has not been studied. Given the half-life of lidocaine, perhaps an infusion should be stopped an hour prior to administering this block. This is important for future studies to investigate.

\section{Conflicts of Interest}

The authors declare no conflicts of interest regarding the publication of this paper.

\section{References}

[1] Kehlet, H., Jensen, T.S. and Woolf, C.J. (2006) Persistent Postsurgical Pain: Risk Factors and Prevention. The Lancet, 367, 1618-1625.

https://doi.org/10.1016/S0140-6736(06)68700-X

[2] Katz, J. and Seltzer, Z. (2009) Transition from Acute to Chronic Postsurgical Pain: Risk Factors and Protective Factors. Expert Review of Neurotherapeutics, 9, 723-744. https://doi.org/10.1586/ern.09.20

[3] Lancaster, R.B., Balkin, D. and Esserman, L. (2016) Post Mastectomy Pain Syndrome Management. Current Surgery Reports, 4, Article No. 13.

https://doi.org/10.1007/s40137-016-0133-6

[4] Reddi, D. and Curran, N. (2014) Chronic Pain after Surgery: Pathophysiology, Risk Factors and Prevention. Postgraduate Medical Journal, 90, 222-227. https://doi.org/10.1136/postgradmedj-2013-132215

[5] Gerbershagen, H.J., Pogatzki-Zahn, E., Aduckathil, S., Peelen, L.M., Kappen, T.H., van Wijck, A.J.M., et al. (2014) Procedure-Specific Risk Factor Analysis for the Development of Severe Postoperative Pain. Anesthesiology, 120, 1237-1245. https://doi.org/10.1097/ALN.0000000000000108

[6] Rudd, R.A., Aleshire, N., Zibbell, J.E. and Gladden, M.R. (2016) Increases in Drug and Opioid Overdose Deaths-United States, 2000-2014. American Journal of Transplantation, 16, 1323-1327. https://doi.org/10.1111/ajt.13776

[7] Scholl, L., Seth, P., Kariisa, M., Wilson, N. and Baldwin, G. (2018) Drug and Opioid-Involved Overdose Deaths-United States, 2013-2017. Morbidity and Mortality Weekly Report, 67, 1419-1427. https://doi.org/10.15585/mmwr.mm675152e1

[8] Moussazadeh, N., Laufer, I., Werner, T., Krol, G., Boland, P., Bilsky, M.H., et al. (2015) Sacroplasty for Cancer-Associated Insufficiency Fractures. Neurosurgery, 76, 446-450. https://doi.org/10.1227/NEU.0000000000000658

[9] Koepke, E.J., Manning, E.L., Miller, T.E., Ganesh, A., Williams, D.G.A. and Manning, M.W. (2018) The Rising Tide of Opioid Use and Abuse: The Role of the Anesthesiologist. Perioperative Medicine, 7, Article No. 16. 
https://doi.org/10.1186/s13741-018-0097-4

[10] Kessler, E.R., Shah, M.K., Gruschkus, S. and Raju, A. (2013) Cost and Quality Implications of Opioid-Based Postsurgical Pain Control Using Administrative Claims Data From a Large Health System: Opioid-Related Adverse Events and Their Impact on Clinical and Economic Outcomes. The Journal of Human Pharmacology and Drug Therapy, 33, 383-391. https://doi.org/10.1002/phar.1223

[11] Joly, V., Richebe, P., Guignard, B., Fletcher, D., Maurette, P., Sessler, D.I. and Chauvin, M. (2005) Remifentanil-Induced Postoperative Hyperalgesia and Its Prevention with Small-Dose Ketamine. Anesthesiology, 103,147-155. https://doi.org/10.1097/00000542-200507000-00022

[12] Brose, W.G. and Cousins, M.J. (1991) Subcutaneous Lidocaine for Treatment of Neuropathic Cancer Pain. Pain, 45, 145-148.

https://doi.org/10.1016/0304-3959(91)90180-6

[13] Kranke, P., Jokinen, J., Pace, N.L., Schnabel, A., Hollmann, M.W., Hahnenkamp, K., et al. (2015) Continuous Intravenous Perioperative Lidocaine Infusion for Postoperative Pain and Recovery. Cochrane Database of Systematic Reviews, No. 7, Article No. CD009642. https://doi.org/10.1002/14651858.CD009642.pub2

[14] Weinberg, L., Peake, B., Tan, C. and Nikfarjam, M. (2015) Pharmacokinetics and Pharmacodynamics of Lignocaine: A Review. World Journal of Anesthesiology, 4, 17-29. https://doi.org/10.5313/wja.v4.i2.17

[15] de Menezes Couceiro, T.C., Lima, L.C., et al. (2014) Intravenous lidocaine to Treat Postoperative Pain. Revista Dor, 15, 55-60.

https://doi.org/10.5935/1806-0013.20140013

[16] Bennett, P.N., Aarons, L.J., Bending, M.R., Steiner, J.A. and Rowland, M. (1982) Pharmacokinetics of Lidocaine and Its Deethylated Metabolite: Dose and Time Dependency Studies in Man. Journal of Pharmacokinetics and Pharmacodynamics, 10, 265-281. https://doi.org/10.1007/BF01059261

[17] Rademaker, A.W., Kellen, J., Tam, Y.K. and Wyse, D.G. (1986) Character of Adverse Effects of Prophylactic Lidocaine in the Coronary Care Unit. Clinical Pharmacology \& Therapeutics, 40, 71-80. https://doi.org/10.1038/clpt.1986.141

[18] Eipe, N., Gupta, S. and Penning, J. (2016) Intravenous Lidocaine for Acute Pain: An Evidence-Based Clinical Update. BJA Education, 16, 292-298. https://doi.org/10.1093/bjaed/mkw008

[19] Ahn, E., Kang, H., Choi, G.J., Park, Y.H., Yang, S.Y., Kim, B.G., et al. (2015) Intravenous lidocaine for Effective Pain Relief After a Laparoscopic Colectomy: A Prospective, Randomized, Double-Blind, Placebo-Controlled Study. International Surgery, 100, 394-401. https://doi.org/10.9738/INTSURG-D-14-00225.1

[20] Andjelković, L., Novak-Jankovič, V., Požar-Lukanovič, N., Bosnić, Z. and Spindler-Vesel, A. (2018) Influence of Dexmedetomidine and Lidocaine on Perioperative Opioid Consumption in Laparoscopic Intestine Resection: A Randomized Controlled Clinical Trial. Journal of International Medical Research, 46, 5143-5154. https://doi.org/10.1177/0300060518792456

[21] De Oliveira, G.S., Duncan, K., Fitzgerald, P., Nader, A., Gould, R.W. and McCarthy, R.J. (2014) Systemic Lidocaine To Improve Quality of Recovery after Laparoscopic Bariatric Surgery: A Randomized Double-Blinded Placebo-Controlled Trial. Obesity Surgery, 24, 212-218. https://doi.org/10.1007/s11695-013-1077-X

[22] Kim, T.H., Kang, H., Hong, J.H., Park, J.S., Baek, C.W., Kim, J.Y., et al. (2011) Intraperitoneal and Intravenous Lidocaine for Effective Pain Relief After Laparoscopic Appendectomy: A Prospective, Randomized, Double-Blind, Placebo-Controlled 
Study. Surgical Endoscopy, 25, 3183-3190.

https://doi.org/10.1007/s00464-011-1684-3

[23] Yon, J., Choi, G., Kang, H., Park, J.-M. and Yang, H. (2014) Intraoperative Systemic Lidocaine for Pre-Emptive Analgesics in Subtotal Gastrectomy: A Prospective, Randomized, Double-Blind, Placebo-Controlled Study. Canadian Journal of Surgery, 57, 175-182. https://doi.org/10.1503/cjs.009613

[24] Terkawi, A.S., Tsang, S., Kazemi, A., Morton, S., Luo, R., Sanders, D.T., et al. (2016) A Clinical Comparison of Intravenous and Epidural Local Anesthetic for Major Abdominal Surgery. Regional Anesthesia and Pain Medicine, 41, 28-36. https://doi.org/10.1097/AAP.0000000000000332

[25] Kuo, C.P., Jao, S.W., Chen, K.M., Wong, C.S., Yeh, C.C., Sheen, M.J. and Wu, C.T. (2006) Comparison of the Effects of Thoracic Epidural Analgesia and i.v. Infusion With Lidocaine on Cytokine Response, Postoperative Pain and Bowel Function In Patients Undergoing Colonic Surgery. British Journal of Anaesthesia, 97, 640-646. https://doi.org/10.1093/bja/ael217

[26] Swenson, B.R., Gottschalk, A., Wells, L.T., Rowlingson, J.C., Thompson, P.W., Barclay, M., et al. (2010) Intravenous Lidocaine Is as Effective as Epidural Bupivacaine in Reducing Ileus Duration, Hospital Stay, and Pain after Open Colon Resection. Regional Anesthesia and Pain Medicine, 35, 370-376. https://doi.org/10.1097/AAP.0b013e3181e8d5da

[27] Marret, E., Rolin, M., Beaussier, M. and Bonnet, F. (2008) Meta-Analysis of Intravenous Lidocaine and Postoperative Recovery after Abdominal Surgery. British Journal of Surgery, 95, 1331-1338. https://doi.org/10.1002/bjs.6375

[28] Terkawi, A.S., Durieux, M.E., Gottschalk, A., Brenin, D. and Tiouririne, M. (2014) Effect of Intravenous Lidocaine on Postoperative Recovery of Patients Undergoing Mastectomy. Regional Anesthesia and Pain Medicine, 39, 472-477. https://doi.org/10.1097/AAP.0000000000000140

[29] Terkawi, A.S., Sharma, S., Durieux, M.E., Thammishetti, S., Brenin. D. and Tiouririne, M. (2015) Perioperative Lidocaine Infusion Reduces the Incidence of Post-Mastectomy Chronic Pain: A Double-Blind, Placebo-Controlled Randomized Trial. Pain Physician, 18, E139-E146.

[30] Wang, L., Guyatt, G.H., Kennedy, S.A., Romerosa, B., Kwon, H.Y., Kaushal, A., et al. (2016) Predictors of Persistent Pain after Breast Cancer Surgery: A Systematic Review and Meta-Analysis of Observational Studies. The Canadian Medical Association Journal, 188, E352-E361. https://doi.org/10.1503/cmaj.151276

[31] Choi, S.J., Kim, M.H., Jeong, H.Y. and Lee, J.J. (2012) Effect of Intraoperative Lidocaine on Anesthetic Consumption, and Bowel Function, Pain Intensity, Analgesic Consumption and Hospital Stay after Breast Surgery. Korean Journal of Anesthesiology, 62, 429-434. https://doi.org/10.4097/kjae.2012.62.5.429

[32] Kendall, M.C., McCarthy, R.J., Panaro, S., Goodwin, E., Bialek, J.M., Nader, A., et al. (2018) The Effect of Intraoperative Systemic Lidocaine on Postoperative Persistent Pain Using Initiative on Methods, Measurement, and Pain Assessment in Clinical Trials Criteria Assessment Following Breast Cancer Surgery: A Randomized, Double-Blind, Placebo-Cont. Pain Practice, 18, 350-359. https://doi.org/10.1111/papr.12611

[33] Bryson, G.L., Charapov, I., Krolczyk, G., Taljaard, M. and Reid, D. (2010) Intravenous Lidocaine Does Not Reduce Length Of Hospital Stay Following Abdominal Hysterectomy. Canadian Journal of Anesthesia, 57, 759-766. https://doi.org/10.1007/s12630-010-9332-2 
[34] Grady, M.V., Mascha, E., Sessler, D.I. and Kurz, A. (2012) The Effect of Perioperative Intravenous Lidocaine and Ketamine on Recovery after Abdominal Hysterectomy. Anesthesia \& Analgesia, 115, 1078-1084. https://doi.org/10.1213/ANE.0b013e3182662e01

[35] Wang T, Liu H, Sun J, Wang L, and Zhang J. (2019) Efficacy of Intravenous Lidocaine in Improving Post-Operative Nausea, Vomiting and Early Recovery after Laparoscopic Gynaecological Surgery. Experimental and Therapeutic Medicine, 17, 4723-4729. https://doi.org/10.3892/etm.2019.7497

[36] Grady, P., Clark, N., Lenahan, J., Oudekerk, C., Hawkins, R., Nezat, G., et al. (2012) Effect of Intraoperative Intravenous Lidocaine on Postoperative Pain and Return of Bowel Function after Laparoscopic Abdominal Gynecologic Procedures. AANA Journal, 80, 282-288.

[37] Xu, S.-Q., Li, Y.-H., Wang, S.-B., Hu, S.-H., Ju, X. and Xiao, J.-B. (2017) Effects of Intravenous Lidocaine, Dexmedetomidine and Their Combination on Postoperative Pain and Bowel Function Recovery after Abdominal Hysterectomy. Minerva Anestesiologica, 83, 685-694.

[38] Weinberg, L., Rachbuch, C., Ting, S., Howard, W., Yeomans, M., Gordon, I., et al. (2016) A Randomised Controlled Trial of Peri-Operative Lidocaine Infusions for Open Radical Prostatectomy. Anaesthesia, 71, 405-410. https://doi.org/10.1111/anae.13368

[39] Lauwick, S., Kim, D.J., Mistraletti, G. and Carli, F. (2009) Functional Walking Capacity as an Outcome Measure of Laparoscopic Prostatectomy: The Effect of Lidocaine Infusion. British Journal of Anaesthesia, 103, 213-219. https://doi.org/10.1093/bja/aep103

[40] Weinberg, L., Jang, J., Rachbuch, C., Tan, C., Hu, R. and McNicol, L. (2017) The Effects of Intravenous Lignocaine on Depth of Anaesthesia and Intraoperative Haemodynamics during Open Radical Prostatectomy. BMC Research Notes, 10, Article No. 248. https://doi.org/10.1186/s13104-017-2570-4

[41] Wuethrich, P.Y., Romero, J., Burkhard, F.C. and Curatolo, M. (2012) No Benefit from Perioperative Intravenous Lidocaine in Laparoscopic Renal Surgery. European Journal of Anaesthesiology, 29, 537-543. https://doi.org/10.1097/EJA.0b013e328356bad6

[42] Jendoubi, A., Naceur, I., Bouzouita, A., Trifa, M., Ghedira, S., Chebil, M., et al. (2017) A Comparison between Intravenous Lidocaine and Ketamine on Acute and Chronic Pain after Open Nephrectomy: A Prospective, Double-Blind, Randomized, Placebo-Controlled Study. Saudi Journal of Anaesthesia, 11, 177-184. https://doi.org/10.4103/1658-354X.203027

[43] Sahmeddini, M.A., Khosravi, M.B. and Farbood, A. (2019) Comparison of Perioperative Systemic Lidocaine or Systemic Ketamine in Acute Pain Management of Patients with Opioid Use Disorder after Orthopedic Surgery. Journal of Addiction Medicine, 13, 220-226. https://doi.org/10.1097/ADM.0000000000000483

[44] Buvanendran, A., Kroin, J.S., Della, Valle, C.J., Kari, M., Moric, M. and Tuman, K. (2010) Perioperative Oral Pregabalin Reduces Chronic Pain after Total Knee Arthroplasty: A Prospective, Randomized, Controlled Trial. Anesthesia \& Analgesia, 110, 199-207.https://doi.org/10.1213/ANE.0b013e3181c4273a

[45] Farag, E., Ghobrial, M., Sessler, D.I., Dalton, J.E., Liu, J., Lee, J.H., et al. (2013) Effect of Perioperative Intravenous Lidocaine Administration on Pain, Opioid Consumption, and Quality of Life after Complex Spine Surgery. Anesthesiology, 119 , 932-940. https://doi.org/10.1097/ALN.0b013e318297d4a5 
[46] Dewinter, G., Moens, P., Fieuws, S., Vanaudenaerde, B., Van de Velde, M. and Rex, S. (2017) Systemic Lidocaine Fails to Improve Postoperative Morphine Consumption, Postoperative Recovery and Quality Of Life In Patients Undergoing Posterior Spinal Arthrodesis. A Double-Blind, Randomized, Placebo-Controlled Trial. British Journal of Anaesthesia, 118, 576-585. https://doi.org/10.1093/bja/aex038 